\title{
Investigating the Effect of Temperature Changes on the Physical Field of Surrounding Rock in a Deep Gold Mine
}

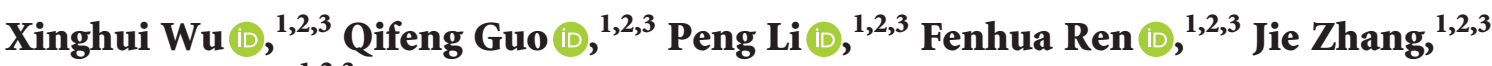 \\ and Meifeng $\mathrm{Cai}^{1,2,3}$ \\ ${ }^{1}$ School of Civil and Resources Engineering, University of Science and Technology Beijing, Beijing 100083, China \\ ${ }^{2}$ Key Laboratory of High-Efficient Mining and Safety of Metal Mines (Ministry of Education of China), \\ University of Science and Technology Beijing, Beijing 100083, China \\ ${ }^{3}$ Beijing Key Laboratory of Urban Underground Space Engineering, University of Science and Technology Beijing, \\ Beijing 100083, China \\ Correspondence should be addressed to Peng Li; pengli@ustb.edu.cn
}

Received 7 May 2021; Revised 17 June 2021; Accepted 15 July 2021; Published 23 July 2021

Academic Editor: Gianfranco Carotenuto

Copyright (c) 2021 Xinghui Wu et al. This is an open access article distributed under the Creative Commons Attribution License, which permits unrestricted use, distribution, and reproduction in any medium, provided the original work is properly cited.

To explore the fracture mechanism of surrounding rock for thermal-mechanical coupling in deep mining, the theoretical solution of the internal temperature and stress evolution of the underground chamber cold boundary subjected to cold impact was obtained by thermoelastic theory. The conduction law of temperature and the evolution characteristics of stress were studied by theoretical formulas, and the influence of the convective heat transfer coefficient on the rate of tensile stress reduction was analyzed. The results show that the theoretical solution is in good agreement with the field measured value, which proves that the theoretical calculation method adopted in this paper is reliable and accurate. When the surface of the underground chamber is impacted by the change of temperature, the cold boundary temperature drops sharply at first, then gradually slows down, and finally reaches the same temperature as the air; the tensile stress decreases sharply from the initial high-stress value, then gradually decreases, and finally tends to be stable. The effects of different convective heat transfer coefficients on the change of temperature resistance of rocks were considered by numerical simulation. The numerical simulation results show that increasing the convective heat transfer coefficient not only increases the tensile stress of the heat transfer boundary but also increases the possibility of cracks, which makes the rock easier to crack. Based on the research results, we introduced the thermal-mechanical coupling disturbance range coefficient $\beta=L / 2 D(\beta=6-8)$ and proposed that the convective heat transfer coefficient is the reference index of the deep mining support structure, which can provide a theoretical basis and technical support for the selection of support materials.

\section{Introduction}

In situ stress is the natural stress existing in the stratum and not disturbed by engineering. In deep mining, the surrounding rock bears not only the in situ stress but also the thermal stress caused by temperature change under the condition of mine ventilation and cooling. Rock deformation caused by thermal stress will be constrained by in situ stress, so in situ stress can be used as the boundary load of the rock physical field. With the gradual development of deep mining, thermal stress has become an increasingly prominent problem, which poses a great threat to mine production [1-3]. Thermal stress is a major factor leading to rock fracture, and its fracture mechanism has received increasing attention. Thermal stress can transform the fracture structure of rock, which affects the physical and mechanical properties of the rock mass. This type of stress is not conducive to the stability of mining and reduces the economic benefits of the mine.

At present, many scholars have performed experimental studies on the physical and mechanical properties of rock under high-temperature conditions. Xia et al. $[4,5]$ used 
granite in the Gonghe Basin, Qinghai Province, to discuss high-temperature thermal damage mechanics. The experimental results showed that the mechanical parameters of granite change with temperature, and the rock changes from brittleness to plasticity with increasing temperature. Chen et al. [6] utilized Beishan granite as the study object and carried out compression fracture and acoustic emission tests of thermally damaged rock samples with different sizes and confining pressures. The results showed that the critical brittle-ductile transition temperature of rock increases with increasing aspect ratio and the existence of a confining pressure effect can inhibit crack growth due to thermal stress. Hu et al. [7] carried out temperature and stress cycling tests on granite. The results showed that the elastic modulus of rock increases with the number of cycles, and it was considered that the stability of rock under the condition of deformation is more in line with the experimental law than that under the condition of strength.

The thermal stress is caused by an uneven expansion force after high-temperature treatment, and a mechanical effect also occurs when the rock is cooled rapidly after being stabilized at a high temperature [8-12]. Zhu et al. [13] concluded that the rock exhibited obvious plastic properties at $300^{\circ} \mathrm{C}$ and produced a large number of cracks when cooled by water at different temperatures. Wang et al. [14] conducted cold and thermal shock experiments on raw coal under four temperature difference conditions and found that temperature shock promoted the initiation of cracks in the coal body, and the cracks expanded and widened. Jin et al. [15] selected granite treated by rapid cooling at $20^{\circ} \mathrm{C}-600^{\circ} \mathrm{C}$ as a study object and carried out physical and mechanical property tests after rapid cooling at different temperatures. The results showed that, with increasing temperature, the tensile strength of granite decreased monotonically after rapid cooling.

The preliminary experimental results of rock thermal cracking showed that thermal cracking can change the microstructure of rock and increase the length and density of the crack at the same time [16]. In the above tests, the rock samples are mainly heated or cooled rapidly to generate thermal stress, thus achieving the effect of thermal fracture. In addition to the experimental study of rock samples, some scholars believe that injecting low-temperature liquid into the rock stratum will cause contraction of the rock stratum and generate tensile stress, which is conducive to the cracking of the reservoir [17-19]. The fracture of materials caused by cold shock at low temperature was widely used in ceramic materials at first. In the study of the thermal shock of rock, Bazant et al. [20] investigated the thermal shock of dry granite by a numerical simulation method. The experiment above analyzed the evolution process of the physical and mechanical properties of the rock cold impact process. Furthermore, many scholars have performed theoretical studies. $\mathrm{Xu}$ et al. [21] studied the thermoelastic-plastic mechanical properties of rock under the action of high temperature and high pressure and deduced the characteristic constitutive equation of rock thermoelastic mechanics. Gong et al. [22] established a thermal-mechanical coupled elastoplastic damage constitutive model for clay.
In addition to theoretical and experimental studies, in actual geothermal exploitation projects, cold water is injected into hot wells, the heat exchange between cold water and hot rock will also have a strong temperature impact on the hot rock, and the induced fractures will help to increase the heat exchange channel and improve the heat recovery efficiency [23]. In addition, cold water will also dash against the geothermal well wall, resulting in the phenomenon of well wall fracture and hole collapse, which affects the safe application and economic benefits of geothermal wells [24]. In the process of deep mining, it is necessary to ventilate and water the tunnel chamber, and the air, water, and hightemperature surrounding rock will undergo a heat exchange, which forms a change of temperature process during the ventilation and watering processes. The deformation of the surrounding rock caused by the combined action of thermal stress and the original rock stress of deep rock increases the difficulty of mining.

The Sanshandao gold mine is a coastal mine with a mining depth greater than $1000 \mathrm{~m}$. With increasing mining depth, the ground temperature, in situ stress state, and geological conditions have become increasingly complex. Therefore, the stress of the surrounding rock becomes increasingly serious, and accidents such as deformation, collapse, roof fall, and spalling of the surrounding rock increase daily. To solve a series of problems of the surrounding rock in deep mining, we utilized the coastal mine, that is, Sanshandao gold mine, as the study object and preliminarily discussed the law of thermal stress coupling the environmental stress evolution of surrounding rock.

\section{Thermal Stress and In Situ Stress Characteristics of the Surrounding Rock}

2.1. Theoretical Calculation Model of Thermal Stress. In the process of high-temperature underground mining, the temperature difference between the chamber and the surrounding rock causes the cold boundary of the surrounding rock to conduct heat. The change in temperature causes the expansion or contraction of the rock. However, the constraint between rock particles will limit the deformation between particles, resulting in the formation of thermal stress between particles. The transient heat conduction differential equation of a solid in a space coordinate system can be expressed as follows [25]:

$$
\gamma\left(\frac{\partial^{2} T}{\partial x^{2}}+\frac{\partial^{2} T}{\partial y^{2}}+\frac{\partial^{2} T}{\partial z^{2}}\right)=\rho c \frac{\partial T}{\partial t}
$$

where $T$ is the instantaneous temperature of the rock at time $t ; \gamma$ is the thermal conductivity of the material; $\rho$ is the density of the material; $c$ is the constant pressure heat capacity of the rock; and $x, y$, and $z$ are the spatial coordinates.

To ensure the definite solution of the differential equation of space heat conduction, it is necessary to know the initial boundary conditions of the studied object, which refers to the initial temperature distribution of the object: 


$$
T_{0}(x, y, z)=f_{0}(x, y, z),
$$

where $T_{0}$ is the temperature distribution at the initial time and $f_{0}$ is the temperature distribution function, which is a certain value.

The temperature distribution function represents the heat conduction and temperature change function at the interface between the object and the outside world, and there are three kinds of boundary conditions. The chamber excavation studied in this paper is considered to be a solidliquid/gas heat exchange process, and the heat conduction of the surrounding rock can be discussed as a two-dimensional object. Therefore, Newton's law of cooling is satisfied on the contact boundary between solid and liquid/gas; that is,

$$
-\gamma\left(\frac{\partial T}{\partial n}\right)_{\Delta}=H\left(T_{s}-T_{f}\right),
$$

where $T_{f}$ is the temperature of the chamber, $\partial T / \partial n$ is the temperature gradient of the surrounding rock, $\Delta$ is the boundary that meets the temperature boundary conditions, and $H$ is the convection heat transfer coefficient of the surrounding rock and chamber air.

It is important to determine the distribution of the thermal field to obtain the stress distribution caused by the interaction of temperature and external load. For the surrounding rock of the circular arch chamber shown in Figure 1 , if the chamber surface suffers a change of temperature,

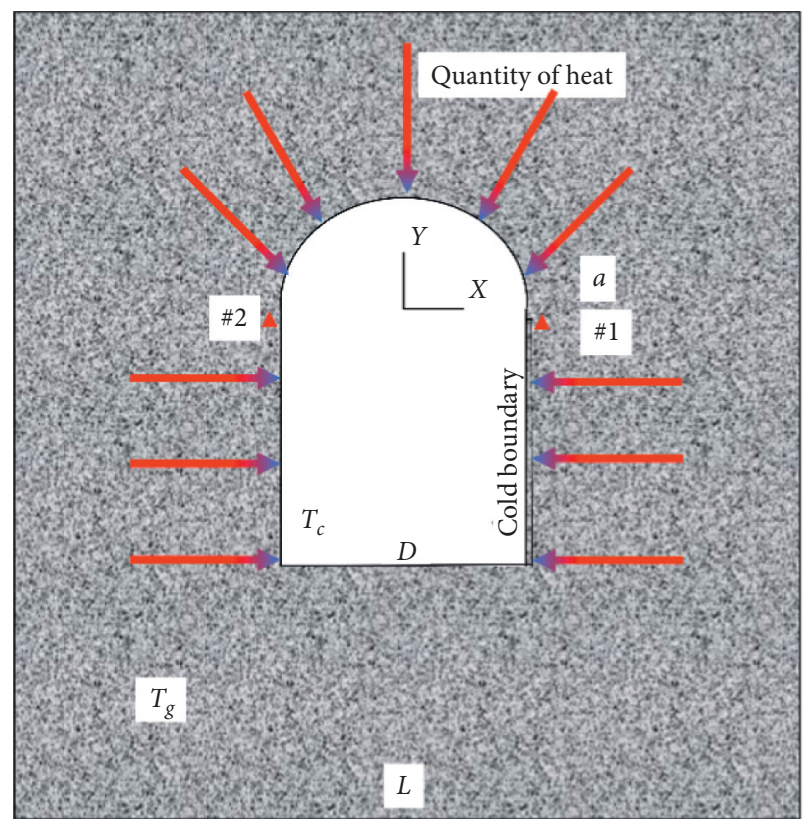

Figure 1: Model of the underground circular arch chamber.

then it can be simplified as a one-dimensional heat conduction problem. The temperature distribution in the solid can be obtained by solving the relevant mathematical equations:

$$
\frac{T(x, t)-T_{0}(x)}{T_{f}-T_{0}(x)}=\operatorname{erfc}\left(\frac{x}{2 \sqrt{\alpha t}}\right)-\exp \left(\frac{H x}{\gamma}+\frac{H^{2} \alpha t}{\gamma^{2}}\right) \cdot \operatorname{erfc}\left(\frac{x}{2 \sqrt{\alpha t}}+\frac{H \sqrt{\alpha t}}{\gamma}\right)
$$

where $T(x, t)$ is the temperature distribution in the solid at any time; $T_{0}(x)$ is the initial temperature distribution of the solid; $\alpha=\gamma /(\rho \cdot C)$ is the thermal conductivity; and $\operatorname{erfc}(\cdot)$ is the Gaussian complementary error function; that is,

$$
\operatorname{erfc}(r)=1-\frac{2}{\sqrt{\pi}} \int_{0}^{r} e^{-z^{2}} \mathrm{~d} z \text {. }
$$

If the temperature gradient and convective heat transfer coefficient of the surrounding rock are changed, then the internal thermal field and thermal stress will also be changed. To study the influence of the convective heat transfer coefficient on the thermal field, the temperature distribution of the surrounding rock at any time is given by

$$
\begin{aligned}
T(x, t) & =\left[\operatorname{erfc}\left(\frac{x}{2 \sqrt{\alpha t}}\right)-\exp \left(\frac{H x}{\gamma}+\frac{H^{2} \alpha t}{\gamma^{2}}\right) \cdot \operatorname{erfc}\left(\frac{x}{2 \sqrt{\alpha t}}+\frac{H \sqrt{\alpha t}}{\gamma}\right)\right] \cdot\left(T_{f}-T_{0}(x)\right) \\
H & =\frac{-\gamma(\partial T / \partial n)_{\Delta}}{T_{s}-T_{f}}
\end{aligned}
$$

It is assumed that the change of temperature boundary is taken as the study object, and the surrounding rock is long enough in the cold boundary, which belongs to the plane stress problem. It can be seen from equation (6) that the temperature changes only in the $X$ direction, and the stress produced will be mainly tensile in the $Y$ direction. Assuming that the cold boundary shown in Figure 1 is free, that is, there is no restriction or external force, the thermal stress distribution in the cold boundary at different times can be obtained by solving the relevant thermoelastic mechanical equations: 


$$
\sigma_{y}=-\alpha \operatorname{ET}(x, t)+\frac{\alpha E}{b} \int_{0}^{b} T(x, t) \mathrm{d} y+\frac{12 \alpha E}{b^{3}} \cdot \int_{0}^{b} T(x, t) \mathrm{d} y
$$

where $\sigma_{y}$ is the stress in the $Y$ direction generated by temperature, $\alpha$ is the thermal expansion coefficient of the surrounding rock, and $E$ is the elastic modulus of the surrounding rock.

When the temperature in the surrounding rock is evenly distributed, that is, $H=0$, no heat conduction occurs, and there is no thermal stress in the plate. Then, it can be observed that, in the initial state of the rock mass without excavation, there is no thermal stress in the surrounding rock because of the initial temperature of the uniform distribution of the rock mass. When the high-temperature rock mass is excavated, the temperature difference between the surrounding rock and the chamber results in thermal stress. Equation (8) is the temperature stress distribution in the laboratory-scale model. Its main purpose is to better analyze and understand the experimental results observed in the laboratory. In practical engineering, it is necessary to consider the temperature stress caused by the overall deformation limitation in most cases. If the upper and lower side constraints of the cold boundary of the model shown in Figure 1, together with the internal constraints, are equivalent to the constraint state of the actual formation, then to estimate the temperature stress distribution, the two terms at the right end of equation (8) need to be removed; that is, the distribution of the temperature stress is $\sigma_{y}=-\alpha E T(x, t)$. The stress distribution of the whole formation under the action of change of temperature thermal stress and original rock in situ stress can be obtained by superimposing the thermal stress on the original rock in situ stress field. Equation (8) shows that the tensile stress in the $Y$ direction is generated due to the temperature gradient distribution in the surrounding rock of the chamber, so it can be predicted that the top and bottom plates are most likely to be damaged in the chamber.

It can be seen from equations (7) and (8) that the distribution of temperature and stress caused by the excavation of a high-temperature mine chamber is affected by many parameters. In this paper, the corresponding stress sensitivity analysis was carried out for different convective heat transfer coefficients by changing the calculation radius and temperature of the surrounding rock.

2.2. In Situ Stress Measurement of the Rock Mass. The measurement of in situ stress is a necessary prerequisite to determine the stability of the surrounding rock and for the numerical simulation of in situ stress. Therefore, it is vital to master the latest in situ stress state of the deep original rock and provide accurate stress environment conditions for the stability analysis and support design of the surrounding rock of the chamber. The overall distribution law of in situ stress in the deep part of the mining area is determined through the combination of field measurements and laboratory tests. Accurate initial stress conditions for the simulation of the cold impact of high-temperature surrounding rock can be provided.

A roadway far away from the stope was selected for the in situ stress measurement, and the size and direction of the in situ stress were measured by the stress relief method of the casing hole. The process of in situ stress acquisition is shown in Figure 2. After obtaining an in situ stress relief curve, an indoor confining pressure calibration test was carried out for the inclusion to obtain parameters such as the rock elastic modulus and Poisson's ratio [26]. The value and direction of the in situ stress at a depth of $960 \mathrm{~m}$ were determined, as shown in Table 1.

Combined with the in situ stress measurement results in the shallow and deep parts of the Xishan mining area of the gold mine, a regression analysis of the in situ stress field model of the mining area was carried out [27]. The data of the in situ stress field at each level are summarized in Table 2.

The distribution characteristics and linear fitting results of in situ stress data in the Xishan mining area are presented in Figure 3.

Regression equation (in situ stress field model) is as follows:

$$
\begin{aligned}
& \sigma_{1}=0.04 D+3.13, \\
& \sigma_{2}=0.03 D+0.83, \\
& \sigma_{3}=0.03 D+1.42,
\end{aligned}
$$

where $\sigma_{1}$ is the maximum horizontal principal stress, $\mathrm{MPa}$; $\sigma_{3}$ is the minimum horizontal principal stress, MPa; $\sigma_{v}$ is the vertical principal stress, $\mathrm{MPa}$; and $D$ is the depth, $\mathrm{m}$. The measurement of the magnitude and direction of in situ stress can provide a real stress boundary condition for the thermalmechanical coupling of a $960 \mathrm{~m}$ underground chamber rock mass.

\section{Numerical Calculation Model}

3.1. Physical and Mechanical Parameters of the Surrounding Rock. The thermal field and stress field of the surrounding rock in deep underground mines interact with each other. Zhang et al. [28] proposed that the physical and mechanical properties of rock changed with temperature. To ensure the accuracy of the stress analysis results of the surrounding rock, it is necessary to consider the influence of temperature on the mechanical properties of rock. The influence of temperature on the thermodynamic properties of the concrete support structure is small, so this aspect is not considered in this paper.

First, the rock mechanical parameters were obtained through the basic mechanical test. In the test, the rock samples were taken from the granite at a depth of $960 \mathrm{~m}$ in the gold mine. The main mineral components of the granite were plagioclase, potash feldspar, quartz, and biotite, with volume fractions of $44 \%, 20 \%, 32 \%$, and $4 \%$, respectively. The main mineral sizes varied from 2 to $4 \mathrm{~mm}$. The rock sample was processed into a cylinder with a size of $50 \mathrm{~mm} \times 100 \mathrm{~mm}$. The mechanical parameters obtained from the final test are shown in Table 3. Via uniaxial and triaxial tests, Yang et al. [29] found that the strength and 


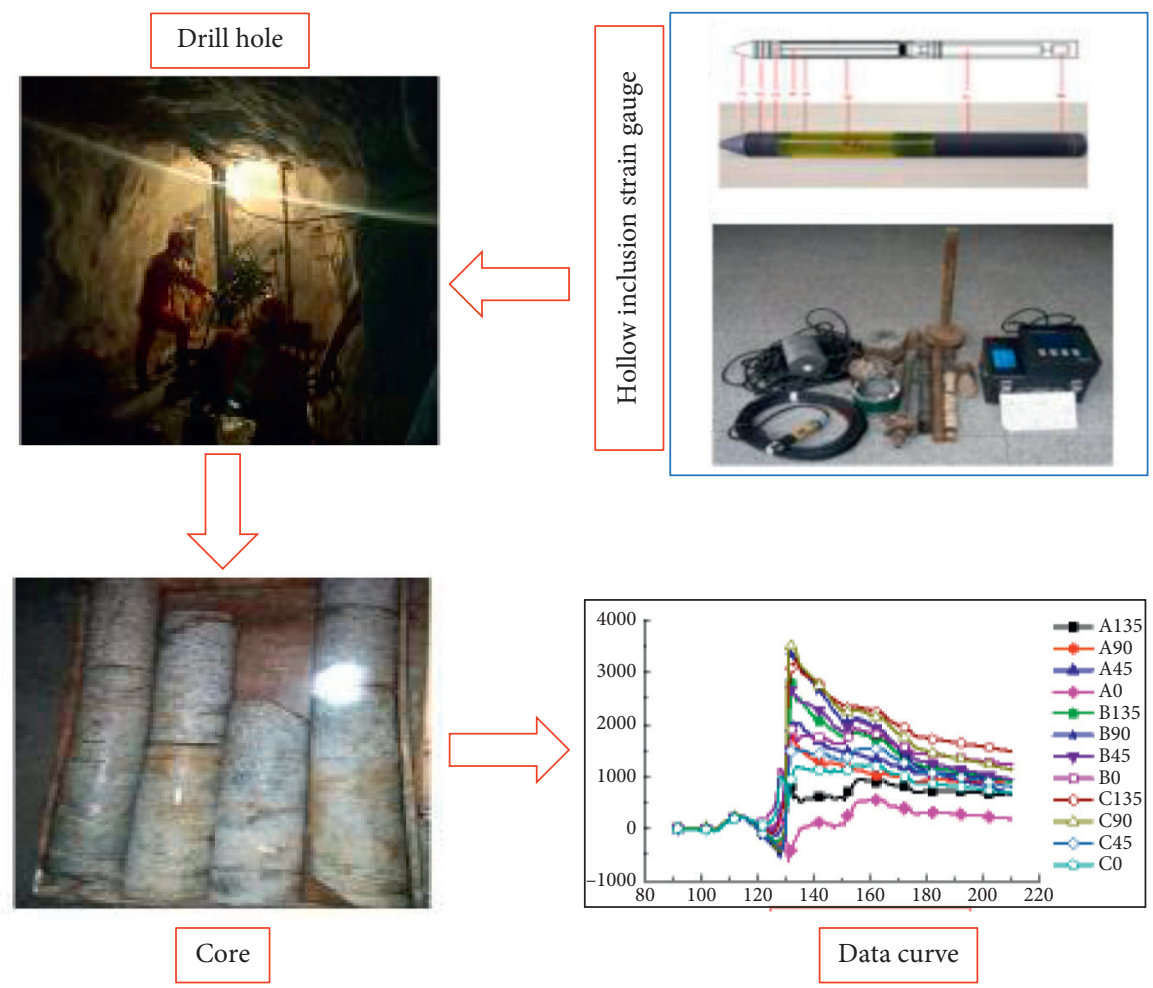

FIGURE 2: Flowchart of in situ stress measurement.

TABLE 1: In situ stress measurement results at a depth of $960 \mathrm{~m}$.

\begin{tabular}{lcccccccc}
\hline $\begin{array}{l}\text { Depth } \\
(\mathrm{m})\end{array}$ & $\begin{array}{c}\text { Horizontal maximum principal stress } \sigma_{1} \\
\text { Value }\end{array}$ & \multicolumn{3}{c}{ Vertical principal stress $\sigma_{v}$} & \multicolumn{3}{c}{ Horizontal minimum principal stress $\sigma_{3}$} \\
$(\mathrm{MPa})$ & Direction $\left(^{\circ}\right)$ & Dip angle $\left(^{\circ}\right)$ & $\begin{array}{c}\text { Value } \\
(\mathrm{MPa})\end{array}$ & Direction $\left(^{\circ}\right)$ & $\begin{array}{c}\text { Dip angle } \\
\left({ }^{\circ}\right)\end{array}$ & $\begin{array}{c}\text { Value } \\
(\mathrm{MPa})\end{array}$ & $\begin{array}{c}\text { Direction }\left({ }^{\circ}\right) \\
\text { Dip angle } \\
\left({ }^{\circ}\right)\end{array}$ \\
\hline 960 & 41.63 & 145.30 & -10.30 & 26.79 & 165.50 & 60.30 & 25.42 & 200.20 \\
\hline
\end{tabular}

TABLE 2: The results of the in situ stress measurement at depths of 75-750 m.

\begin{tabular}{|c|c|c|c|c|c|c|c|c|c|}
\hline \multirow{2}{*}{$\begin{array}{l}\text { Depth } \\
\text { (m) }\end{array}$} & \multicolumn{3}{|c|}{ Horizontal maximum principal stress $\sigma_{1}$} & \multicolumn{3}{|c|}{ Vertical principal stress $\sigma_{v}$} & \multicolumn{3}{|c|}{ Horizontal minimum principal stress $\sigma_{3}$} \\
\hline & $\begin{array}{l}\text { Value } \\
\text { (MPa) }\end{array}$ & Direction $\left({ }^{\circ}\right)$ & Dip angle $\left({ }^{\circ}\right)$ & $\begin{array}{l}\text { Value } \\
(\mathrm{MPa})\end{array}$ & Direction $\left(^{\circ}\right)$ & Dip angle $\left({ }^{\circ}\right)$ & $\begin{array}{l}\text { Value } \\
(\mathrm{MPa})\end{array}$ & Direction $\left({ }^{\circ}\right)$ & Dip angle $\left({ }^{\circ}\right)$ \\
\hline 75 & 6.01 & 288.50 & -6.30 & 2.56 & 250.40 & 82.00 & 3.81 & 198.00 & -4.90 \\
\hline 150 & 7.73 & 280.90 & -5.20 & 4.50 & 27.70 & 72.50 & 5.48 & 9.40 & 16.60 \\
\hline 420 & 19.27 & 284.10 & -21.30 & 10.88 & 134.4 & -65.70 & 11.05 & 18.50 & -11.10 \\
\hline 420 & 19.39 & 120.40 & -14.90 & 10.92 & 169.20 & 68.10 & 9.44 & 34.70 & 15.80 \\
\hline 510 & 24.55 & 129.00 & 4.00 & 14.49 & 133.00 & -85.00 & 16.35 & 222.00 & 2.00 \\
\hline 510 & 24.64 & 249.00 & 3.00 & 15.68 & 155.00 & 82.00 & 15.02 & 161.00 & -10.00 \\
\hline 555 & 25.71 & 315.00 & -13.00 & 14.00 & 14.00 & 73.00 & 13.00 & 50.00 & -20.00 \\
\hline 600 & 28.88 & 103.00 & 1.00 & 16.54 & 10.00 & 76.00 & 14.77 & 13.00 & -8.00 \\
\hline 600 & 30.17 & 110.00 & -16.00 & 16.94 & 236.00 & -70.00 & 18.83 & 24.00 & -11.00 \\
\hline 645 & 29.57 & 112.00 & -3.00 & 19.56 & 1.00 & -80.00 & 15.48 & 204.00 & -9.00 \\
\hline 690 & 31.50 & 280.00 & 2.00 & 19.08 & 230.00 & -79.00 & 17.54 & 10.00 & -10.00 \\
\hline 690 & 29.77 & 277.00 & 4.00 & 20.84 & 352.00 & -74.00 & 19.63 & 8.00 & 15.00 \\
\hline 750 & 32.78 & 105.60 & -0.59 & 19.60 & 18.70 & 79.20 & 16.68 & 15.50 & -10.80 \\
\hline 750 & 33.22 & 119.00 & -10.00 & 19.93 & 271.00 & -82.00 & 17.10 & 208.00 & -8.00 \\
\hline 780 & 30.72 & 133.30 & -14.90 & 18.09 & 149.70 & 74.50 & 26.41 & 224.40 & -4.170 \\
\hline 960 & 41.63 & 145.30 & -10.30 & 26.79 & 165.50 & 60.30 & 25.42 & 200.20 & -6.21 \\
\hline
\end{tabular}

deformation properties of granite samples after high-temperature treatment and real-time high-temperature treatment were not significantly different at the same confining pressure level, so the mechanical test of surrounding rock at a depth of $960 \mathrm{~m}$ did not need to be carried out under realtime high-temperature conditions. According to the theory 


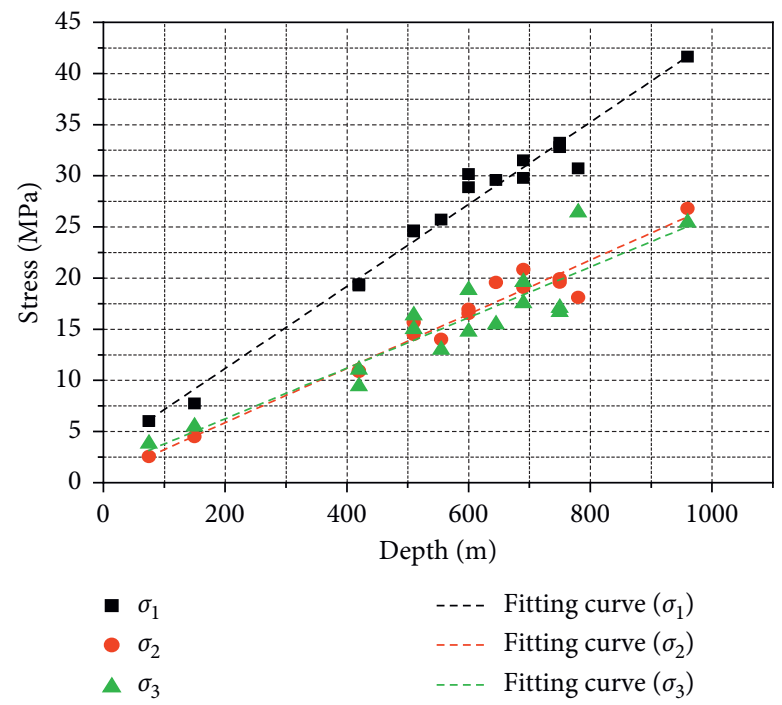

Figure 3: Linear fitting of $\sigma_{1}, \sigma_{v}$, and $\sigma_{3}$ with depth.

TABLE 3: Thermodynamic parameters of the surrounding rock.

\begin{tabular}{|c|c|c|c|c|c|c|}
\hline $\begin{array}{l}\text { Temperature } \\
\left({ }^{\circ} \mathrm{C}\right)\end{array}$ & $\begin{array}{c}\text { Modulus of } \\
\text { elasticity }(\mathrm{GPa})\end{array}$ & $\begin{array}{l}\text { Poisson's } \\
\text { ratio }\end{array}$ & $\begin{array}{l}\text { Coefficient of thermal } \\
\text { expansion }\left(10^{-6{ }^{\circ}} \mathrm{C}\right)\end{array}$ & $\begin{array}{l}\text { Constant pressure heat } \\
\text { capacity } J \cdot\left(\mathrm{kg} \cdot{ }^{\circ} \mathrm{C}\right)^{-1}\end{array}$ & $\begin{array}{l}\text { Thermal conductivity } \\
\qquad W \cdot\left(\mathrm{m} *{ }^{\circ} \mathrm{C}\right)^{-1}\end{array}$ & $\begin{array}{l}\text { Density } \\
\left(\mathrm{kg} \cdot \mathrm{m}^{-3}\right)\end{array}$ \\
\hline 60 & \multirow{4}{*}{42.79} & \multirow{4}{*}{0.25} & 5.30 & 1102 & 3.22 & \multirow{4}{*}{2680} \\
\hline 70 & & & 6.20 & 1114 & 3.16 & \\
\hline 80 & & & 7.50 & 1126 & 3.11 & \\
\hline 90 & & & 8.40 & 1138 & 3.06 & \\
\hline
\end{tabular}

of rock thermodynamics and the physical and mechanical characteristics of high-temperature rock, combined with engineering measurements and the built-in material parameters of the COMSOL material library provided by the literature [30], the physical and thermodynamic parameters of the surrounding rock at a $960 \mathrm{~m}$ depth, such as the thermal expansion coefficient and the thermal conductivity coefficient, were finally determined, as shown in Table 3. Table 4 presents the mechanical parameters of granite at a depth of $960 \mathrm{~m}$.

\subsection{Numerical Calculation Model and Boundary Conditions.} Assuming that the effect of groundwater and the supporting structure is not considered, a circular arch chamber $(D=4 \mathrm{~m})$ at $960 \mathrm{~m}$ depth was selected for analysis in this paper. The surrounding rock cavern was calculated by the finite element method based on the rigid model. The excavation and support of the tunnel were realized by the solid heat transfer module and the solid mechanical module in the finite element software. First, two solid mechanics modules were established by using the finite element software COMSOL Multiphysics 5.4. In the solid mechanical module, the gravity load or body load was applied. At the same time, the measured original rock in situ stress was applied to the model in the form of a boundary load. Finally, the initial stress field was balanced by calculation.

According to the field measurement data, the indoor temperature of the chamber after ventilation is $30^{\circ} \mathrm{C}$, and the temperature of the bottom water channel is $5^{\circ} \mathrm{C}$, so the indoor simulation temperature is taken as $5^{\circ} \mathrm{C}, 10^{\circ} \mathrm{C}, 20^{\circ} \mathrm{C}$, and $30^{\circ} \mathrm{C}$. The deep temperature stability value of the surrounding rock is taken as $60^{\circ} \mathrm{C}, 70^{\circ} \mathrm{C}, 80^{\circ} \mathrm{C}$, and $90^{\circ} \mathrm{C}$, and the depth of the chamber is taken as $960 \mathrm{~m}$ depth for the simulation.

\section{Results' Analysis}

4.1. Disturbance Range of Surrounding Rock under Thermal Stress. In the mining process, the study of the loose zone of surrounding rock can guide the design and construction of underground engineering. For the stability of the surrounding rock of the underground chamber, the thermal stress will cause a certain range of damage to the surrounding rock. The underground chamber of a mine can be regarded as an infinite or semi-infinite domain problem. In the application of finite element numerical simulation, if the calculation range is larger than the surrounding rock disturbance range, then it can be regarded as a nonthermal stress. For this problem, the calculation ranges of the surrounding rock proposed by different scholars are different. Referring to the influence of excavation on the rock stress, Cai [31] proposed that, after the excavation of the chamber, only the rock stress within 3-5 times the chamber width from the excavation boundary would be affected, and the excavation disturbance stress beyond the boundary could be ignored. In the high-temperature environment, due to the obvious temperature difference between the interior and 
TABLE 4: Mechanical parameters of granite at a depth of $960 \mathrm{~m}$.

\begin{tabular}{lccccc}
\hline Density $\left(\mathrm{kg} / \mathrm{m}^{3}\right)$ & Bulk modulus $(\mathrm{GPa})$ & Shear modulus $(\mathrm{GPa})$ & Tensile strength $(\mathrm{MPa})$ & Cohesion $(\mathrm{MPa})$ & Friction angle $\left({ }^{\circ}\right)$ \\
\hline 2630 & 9.80 & 7.32 & 5.20 & 8.72 & 32.56 \\
\hline
\end{tabular}

exterior of the surrounding rock of the chamber, thermal stress must also be caused by the temperature difference. It is assumed that when the temperature difference is less than a certain value, the thermal stress is ignored. Thus, the thermal stress of the surrounding rock exists in a certain range. In the numerical analysis, it was assumed that the maximum side length of the square with thermal stress is $L$.

In the simulation, the chamber width is $4 \mathrm{~m}, L$ is taken as $12 \mathrm{~m}, 20 \mathrm{~m}, 24 \mathrm{~m}, 30 \mathrm{~m}, 36 \mathrm{~m}, 40 \mathrm{~m}, 48 \mathrm{~m}$, and $60 \mathrm{~m}$, and the temperature evolution law of point " $a$ " (Figure 1) at the chamber arch waist is taken as the basis to determine $L$. For the convenience of description, the temperature and $Y$ direction stress of point " $a$ " are represented by $T_{a}$ and $F_{a}$, and the chamber temperature and initial surrounding rock temperature are represented by $T_{c}$ and $T_{g}$.

Figure 4 indicates that $T_{a}$ increases linearly with increasing $T_{c}$ and $T_{g}$, and the larger $L$ is, the lower $T_{a}$ is, which means that the larger $L$ is, the smaller the temperature gradient of the surrounding rock is. It can be seen from the linear increasing slope that the change in $T_{g}$ is more sensitive to the increase in $T_{a}$. At the same time, it contributes more to the temperature gradient of the surrounding rock; therefore, the buried depth of the chamber is more important than the influence of the chamber temperature on the thermal stress.

The range of the temperature change caused by chamber excavation is certain. If the calculation area of the surrounding rock exceeds this range, then the temperature at point "a" will not change. From equation (8), it can be seen that the stress of point " $a$ " in the $Y$ direction also tends to be stable. When the temperature and stress reach stable values, the corresponding $L$ is the reasonably calculated side length of the surrounding rock. Assuming that, in the high-temperature environment, the original temperature $T_{g}$ of the rock is $90^{\circ} \mathrm{C}$ and remains stable in an infinite range of the same depth, the internal temperature $T c$ of the chamber is taken as $5^{\circ} \mathrm{C}, 10^{\circ} \mathrm{C}, 20^{\circ} \mathrm{C}$, and $30^{\circ} \mathrm{C}$, and then $T_{a}$ and $F_{a}$ are analyzed.

Figure 5 shows the values of $T_{a}$ and $F_{a}$ when $L$ is $12 \mathrm{~m}$, $20 \mathrm{~m}, 24 \mathrm{~m}, 30 \mathrm{~m}, 36 \mathrm{~m}, 40 \mathrm{~m}, 48 \mathrm{~m}$, and $60 \mathrm{~m}$. Figure $5(\mathrm{a})$ shows that the declining process of $T_{a}$ with $L$ is mainly divided into three stages: rapid decline stage, slow decline stage, and stable stage. When $L$ changes from $12 \mathrm{~m}$ to $30 \mathrm{~m}, T_{a}$ and $F_{a}$ change rapidly, which shows that $L$ has an obvious influence on $T_{a}$ and $F_{a}$ at this stage. When $L$ is $48 \mathrm{~m}, T_{a}$ enters the stable stage and does not change. In Figure 5(b), $F_{a}$ gradually decreases with increasing $L$ and tends to be stable when $L$ is $48 \mathrm{~m}$. The reason is that when $L$ increases, the temperature gradient decreases and the stress value decreases, which is consistent with the theoretical derivation. Therefore, $L=48 \mathrm{~m}$ is taken as the side length of the surrounding rock calculation area; that is, the distance between the center of the chamber and the surrounding rock boundary is $24 \mathrm{~m}$, and the thermal-mechanical coupling disturbance range coefficient $\beta=L / 2 D$, where $\beta$ is $6-8$.

4.2. Analysis of the Surrounding Rock Thermal Field. Combined with the theoretical analysis and numerical simulation results of temperature and stress, the reasonable calculation range of the surrounding rock is finally determined to be $48 \mathrm{~m} \times 48 \mathrm{~m}$ under thermal-mechanical coupling. Figure 6 shows the temperature distribution of the rock mass (Figure 6(a)) and the temperature distribution of different positions during the cold impact of the surrounding rock $\left(T_{c}=30^{\circ} \mathrm{C}, T_{g}=90^{\circ} \mathrm{C}\right.$ ) (Figure $6(\mathrm{~b})$ ). In the early stage of the change of temperature, the temperature rises first at the change of temperature boundary and forms a temperature gradient, and at the same time, the temperature rises slowly at a distance of $8 \mathrm{~m}$ from the boundary. With increasing distance, the high-temperature region gradually forms outside. The curve of the temperature change shows a nonlinear increasing change, which means that the temperature gradients in this direction are different. To learn the change in the temperature gradient, Figure 7 was obtained by taking the derivative of Figure 6(b). Figure 7 shows that the temperature gradient in the same direction decreases nonlinearly, and the closer the distance is to the cold boundary, the greater the temperature gradient is. The temperature gradient can cause the deformation of the surrounding rock to be uncoordinated and produce thermal stress, and a change in the temperature gradient can cause a change in the thermal stress, which also proves that the roof and floor of the surrounding rock cold boundary are most vulnerable to damage.

4.3. Stress Field Analysis of the Surrounding Rock. To study the change in the stress field under thermal-mechanical coupling in deep mining, field data acquisition was carried out. The chamber temperature was $29.6^{\circ} \mathrm{C}$, which was measured by a CWH600 infrared thermometer, and a ZLGH borehole dynamometer was used to monitor the change rule of the surrounding rock stress. The monitoring position is mainly located at positions \#1 and \#2 on both sides of the chamber (Figure 1). A hand-held rock drill was used to drill holes with a diameter of $42 \mathrm{~mm}$ and a depth of $4 \mathrm{~m}$ on the sidewall. During the installation, the stress pillow was placed horizontally, and a $5 \mathrm{MPa}$ stress was preloaded. The GSJ-2A detector and CWH600 infrared thermometer were used to read and analyze the calculation value of stress and temperature in the hole. The data collection interval was 0.5 days.

The numerical calculation results were compared with the field measured data, and the results are shown in Figure 8. From the distribution of temperature and stress, the theoretical solution is in good agreement with the field measured value, which proves that the theoretical 


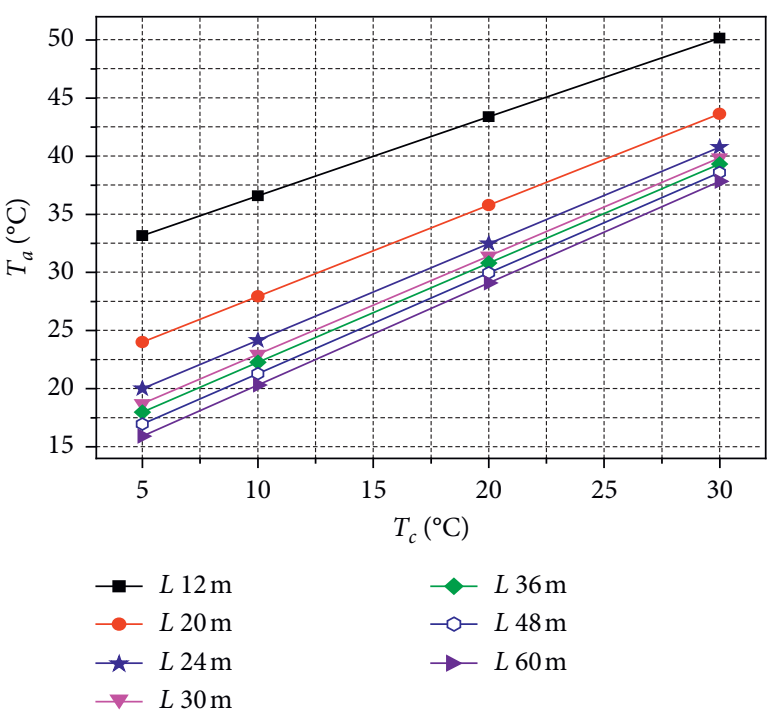

(a)

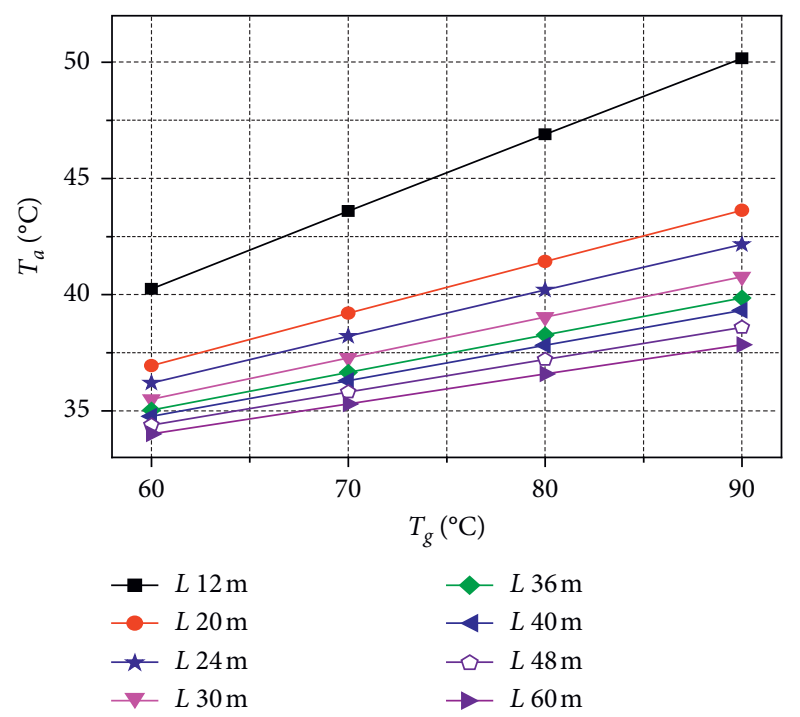

(b)

FIGURE 4: Influence of the chamber and surrounding rock temperature on the temperature gradient: temperature effect of $T_{c}$ on $T_{a}(\mathrm{a})$ and temperature effect of $T_{g}$ on $T_{a}(\mathrm{~b})$.

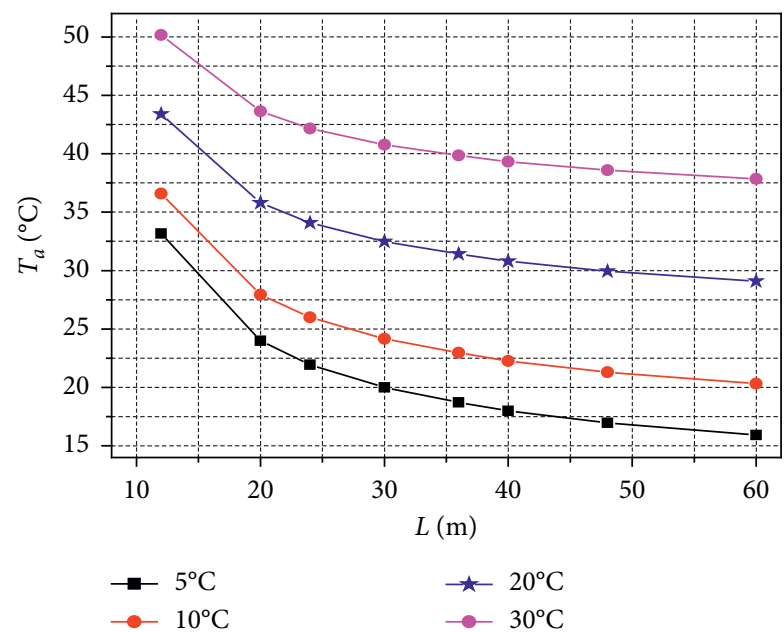

(a)

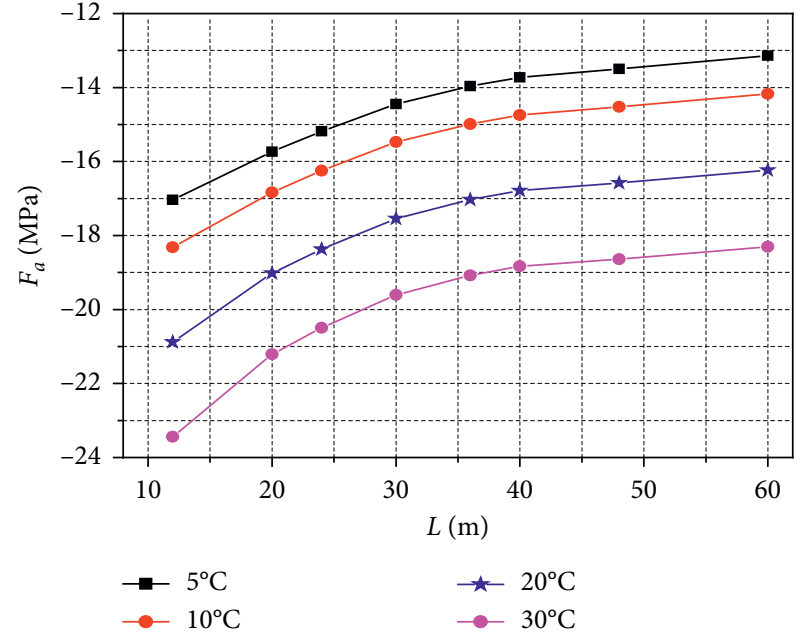

(b)

FiguRE 5: Influence of the side length of different surrounding rock calculation areas on the surrounding rock temperature and stress: influence of $L$ on $T_{a}$ (a) and influence of $L$ on $F_{a}$ (b).

calculation method adopted in this paper is reliable and accurate. In Figure 8, regardless of the stress or temperature change curve, the deformation trend of the measured data is consistent with that of the simulated $T_{g}=60^{\circ} \mathrm{C}$. It can be concluded that the temperature of the formation at a depth of $960 \mathrm{~m}$ in the gold mine is approximately $60^{\circ} \mathrm{C}$. Based on this surrounding rock temperature, the stress evolution law of the underground chamber under thermal-mechanical coupling is discussed.

Figure 8 shows the temperature and stress evolution results obtained by numerical simulation. The process is divided into three stages: initial stage (0-4 days), intermediate stage (4-8 days), and final stage ( $8-10$ days).
Figure 8(a) demonstrates the temperature change curve at different times during the cold impact process and describes the evolution process of the thermal field after chamber excavation. In the early stage of the change of temperature, the cold boundary first exhibits rapid cooling, forming a temperature gradient, and at the same time, the surrounding rock may be fractured randomly at the boundary. With increasing cooling time, the low-temperature area gradually transfers to the interior. In the middle stage, the cooling area moves inward further, and the cooling rate of the cold boundary slows down. At the end of the model, the cooling area covers the whole model, the temperature gradient decreases, and the temperature no longer changes. 


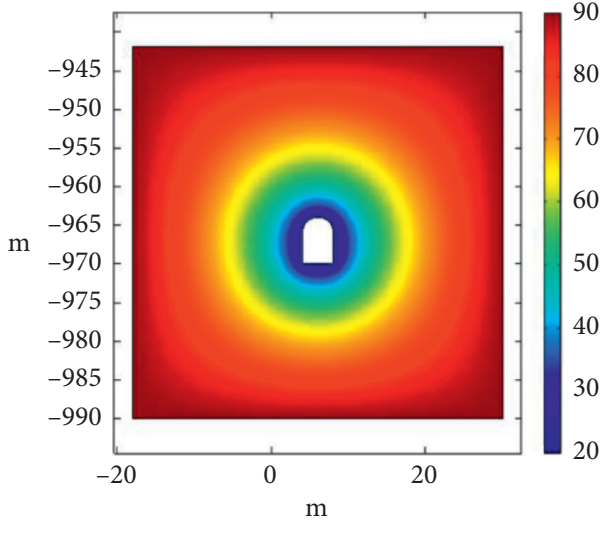

(a)

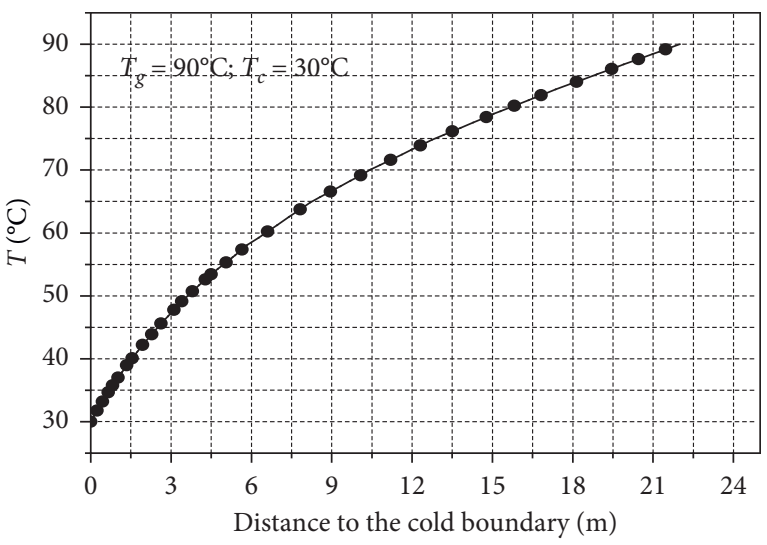

(b)

FIGURE 6: Cloud chart of the thermal field distribution of the surrounding rock (a) and corresponding temperature change curve (b).

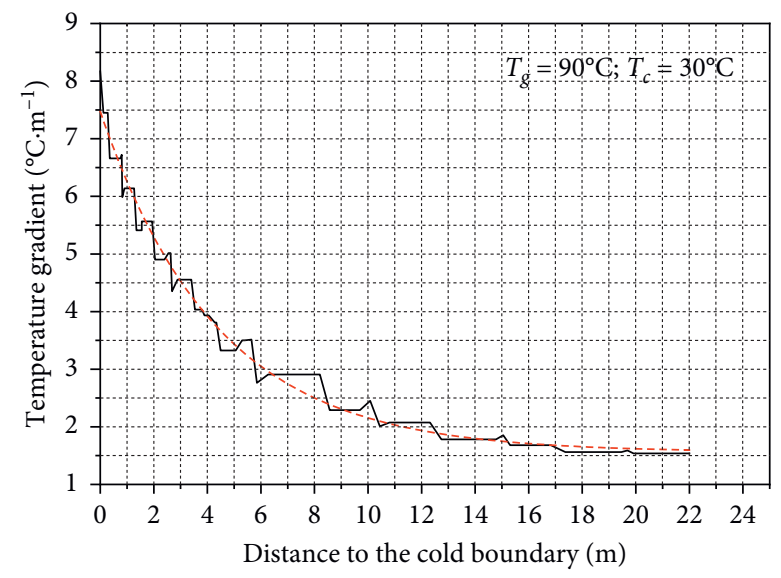

FIgURE 7: The variation in the temperature gradient with distance.

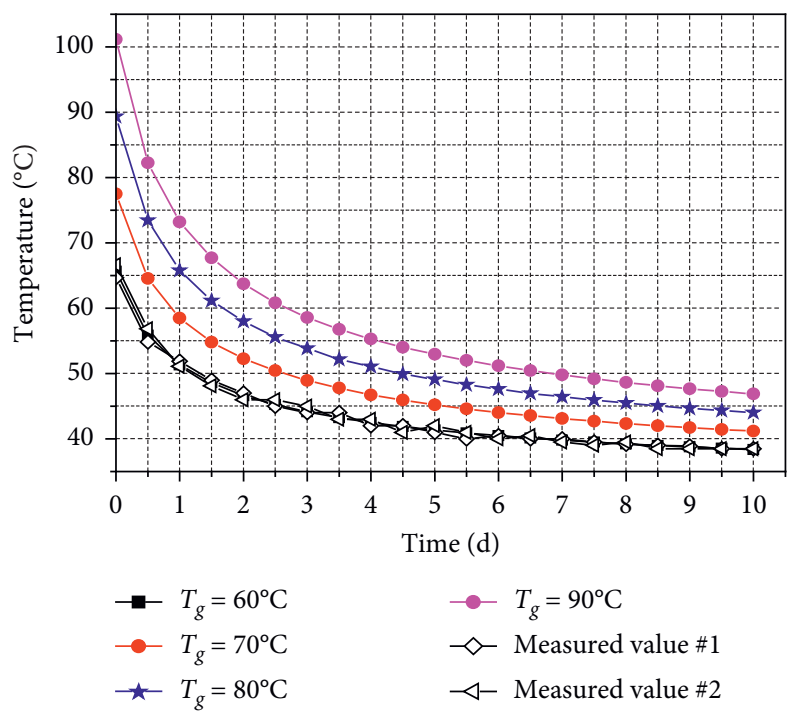

(a)

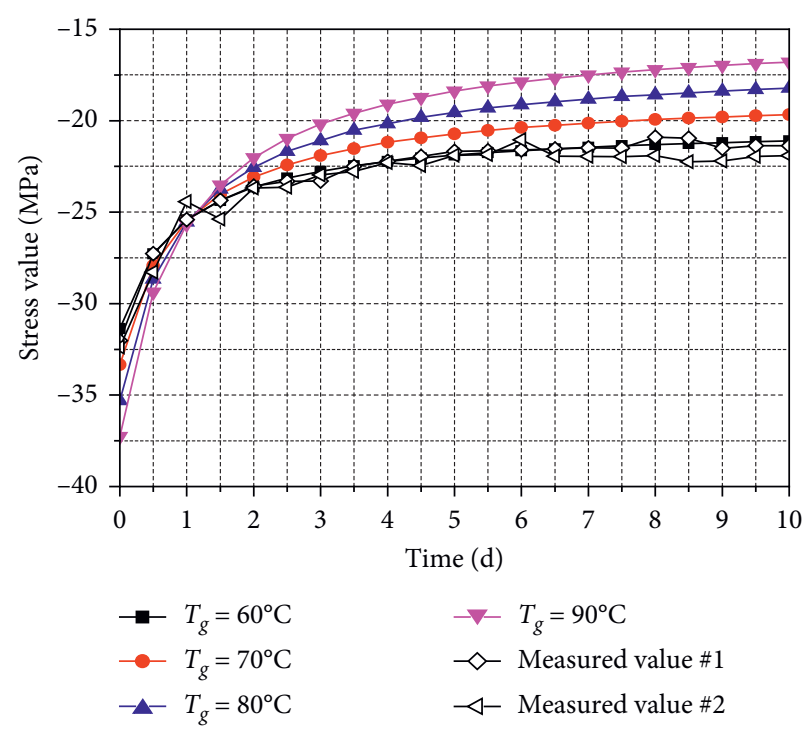

(b)

Figure 8: Comparison of the theoretical solution and field measured data: (a) temperature and (b) stress. 
As illustrated in Figure 8(b), the stress distribution evolution rule of change of temperature is as follows: in the early stage of change of temperature, the higher tensile stress at point " $a$ " is only distributed in a small range near the change of temperature boundary, and the model is in a state of compressive stress. This is because at the beginning of the change of temperature, the temperature gradient is formed rapidly on the cold boundary, and the surrounding rock of the cold boundary is in a state of cold shrinkage, so it is shown as a state of tensile stress. However, there is no cooling in the initial stage of the internal model, and it is in a high-temperature state, so the internal stress of the model is compressive, and the stress is small. It can be seen from the stress evolution process that the tensile stress at point " $a$ " decreases rapidly in a short period because the temperature difference between point " $a$ " and the chamber temperature drops sharply, and the decrease in the temperature difference leads to a decrease in the tensile stress. When the initial tensile stress exceeds the tensile strength of the rock, the surrounding rock begins to fracture; that is, cracks occur at the cold boundary. It is assumed that cracks form near the cold boundary, and the tensile stress is released, so the tensile stress at the boundary will also drop sharply (Figure 8(b)). However, point " $a$ " is still in a state of tensile stress, and with increasing time, the range of tensile stress also increases. In the middle period of the change of temperature, the temperature difference decreases gradually due to the expansion of the temperature range. With increasing time, the tensile stress of the outermost edge decreases sharply, the range of the tensile stress area expands further inward, and the speed of the tensile stress slows down. In the later stage of the change of temperature, the temperature of point " $a$ " almost no longer changes, and the temperature difference tends to be zero and finally forms a stable state.

The results above show that the thermal field is closely related to the change in the stress field and that the two transfer to the surrounding rock in step. It can be concluded that the temperature difference between the interior and exterior of the surrounding rock causes the temperature gradient of the surrounding rock, which results in thermal stress. Under the action of thermal stress (tensile stress), if the stress exceeds the tensile strength of the rock, then cracks will form and develop.

\section{Discussion}

Reducing the heat exchange capacity at the cold boundary can reduce the damage to the surrounding rock $[16,32]$. Jin [33] investigated the influence of flow velocity on the heat transfer coefficient and discovered that these parameters had a linear positive relationship. By controlling the convective heat transfer coefficient, the heat exchange of the surrounding rock can be reduced. Equations (3) and (8) discuss the effect of the convective heat transfer coefficient on temperature and stress and highlight the role of the convective heat transfer coefficient in the thermal stress calculation. By reducing the flow velocity and improving the surface smoothness, the convective heat transfer coefficient can be properly reduced to decrease the rock cracking induced by thermal stress. Although the theoretical analysis can reflect the relationship between relevant parameters, it is difficult to use theoretical methods to obtain the influence of different convective heat transfer coefficients on the stress and temperature change trends. To obtain the effect of the convective heat transfer coefficient on the stress change characteristics, the numerical simulation study is continued using the calculation model shown in Figure 1. The results indicate that the convective heat transfer coefficients (the amount of heat per unit area exchanged with nearby rock mass by convection in $1 \mathrm{~s})$ are $H=200 \mathrm{~W} /\left(\mathrm{m}^{2} \cdot \mathrm{K}\right), 2000 \mathrm{~W} /$ $\left(\mathrm{m}^{2} \cdot \mathrm{K}\right)$, and $2000 \mathrm{~W} /\left(\mathrm{m}^{2} \cdot \mathrm{K}\right)$, which are expressed by models 1,2 , and 3 , respectively. The surrounding rock temperature is $60^{\circ} \mathrm{C}$, while other parameters are the same as the model in Figure 8. Figures 9 and 10 present the time-space evolution process of stress calculated by numerical simulation using different convective heat transfer coefficients. The change of temperature process occurs in three stages: fast, slow, and stable.

Figure 9 shows the time evolution of the cold boundary stress with different convective heat transfer coefficients, which represents the change in stress over time. Generally, the thermal stress of each convective heat transfer coefficient is the tensile stress, indicating that the cold boundary damage is controlled by the tensile stress. In the early stage of the change of temperature, each model has a tensile stress at the cold boundary. Model 1 has a small cooling range and a minimum temperature gradient, so the maximum tensile stress at point " $a$ " is the minimum, and the model is not fractured. The temperature gradients of model 2 and model 3 are higher than that of model 2. There is a high maximum tensile stress in the cold boundary. When the tensile stress is greater than the tensile strength, the boundary of model B and model $\mathrm{C}$ is fractured. In the slow stage, the cooling area expands to the interior. As the cooling area expands, the maximum tensile stress area transfers to the interior, as shown in Figure 10. After model $\mathrm{C}$ experiences the maximum tensile stress, the tensile stress is greater than the tensile strength. Then, cracks are formed in the surrounding rock of model $\mathrm{C}$, which leads to the release of the tensile stress, so the tensile stress of model $\mathrm{C}$ is smaller than that of model A and model B in the stable stage. Although the maximum tensile stress of model B is less than that of model C, cracks also form after going through the slow stage, and the number of cracks is less than that of model $\mathrm{C}$, so the release of tensile stress is not obvious. In the final stable stage, the tensile stress of model B is greater than that of model $\mathrm{C}$ but less than that of model $\mathrm{A}$.

The results above show that the convective heat transfer coefficient has an important influence on the initiation and development of cracks. The convective heat transfer coefficient is too small to produce cracks on the cold boundary. When the tensile stress is greater than the tensile strength, crack initiation occurs. The larger the convective heat transfer coefficient is, the more the cracks develop, and the stronger the fracturing effect is. In the third kind of temperature boundary condition, the heat transfer of the cold boundary increases with increasing convective heat transfer coefficient, which causes the temperature gradient in the 


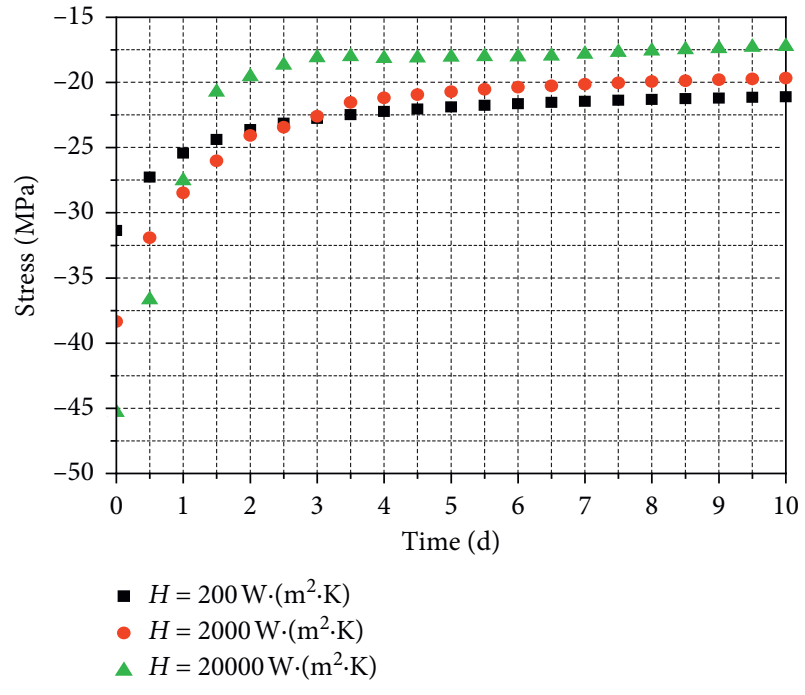

FIGURE 9: Evolution rule of chamber stress with time under different convective heat transfer coefficients.

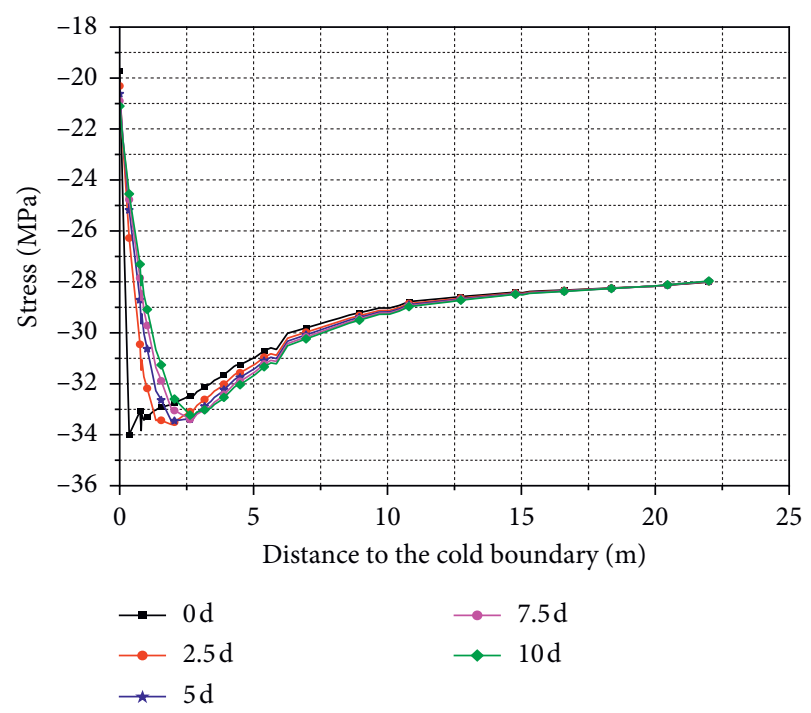

Figure 10: Spatial evolution of stress in the chamber $\left(H=200 \mathrm{~W} /\left(\mathrm{m}^{2} \cdot \mathrm{K}\right)\right)$.

cooling zone to increase. Thus, when the temperature stress increases, the cracks more easily crack, and the number of cracks is larger. To reduce the influence of thermal stress on the chamber, it is suggested that the coefficient of convective heat transfer should be taken as one of the evaluation indexes of the support materials. The reduction in the convective heat transfer coefficient of the support material can ensure not only the stability of the surrounding rock but also the proper temperature of the working environment.

\section{Conclusions}

Based on the theory of thermal stress, the temperature and stress field of the surrounding rock induced by temperature change are studied by numerical simulation and field data. The following can be seen from the results:
(1) Based on the engineering background of coastal mines, combined with the in situ stress data collected in the field and the theoretical calculation of thermal stress, the influence range of thermal-mechanical coupling on the surrounding rock in the process of deep mining is studied. By changing the calculated side length and the surrounding rock temperature, the coefficient of thermal-mechanical coupling disturbance range $\beta=L / 2 D$, where $\beta$ is $6-8$.

(2) The cold boundary of the underground chamber will exchange heat with the high-temperature surrounding rock, which will reduce the temperature inside the rock, and the temperature drops the fastest near the cold boundary and forms a higher temperature gradient to generate great tensile stress. The tensile stress at the cold boundary decreases rapidly first and then slowly, which shows a phenomenon of maximum tensile stress lagging.

(3) The convective heat transfer coefficient between the underground chamber and the surrounding rock has a significant effect on the temperature and stress distribution in the rock. The larger the convective heat transfer coefficient is, the greater the temperature gradient produced by heat conduction is and the higher the corresponding thermal stress is. If the convective heat transfer coefficient of high-temperature rock and support structure is high, then it can achieve a better change of temperature effect; while the convective heat transfer coefficient of rock and support structure is low, the change of temperature effect is affected, which plays the role of protecting the surrounding rock. To improve the role of the supporting structure, it is necessary to further study the convective heat transfer coefficient of the supporting structure.

(4) When the surface of the underground chamber is subjected to the change of temperature, the cold boundary temperature first decreases sharply, then gradually decreases, and finally reaches the same temperature as the surrounding environment. The tensile stress decreases sharply from the initial highstress value, then gradually decreases, and finally stabilizes [34].

\section{Data Availability}

The test data used to support the findings of this study are included within the article.

\section{Conflicts of Interest}

The authors declare that they have no conflicts of interest.

\section{Acknowledgments}

This work was supported by the Interdisciplinary Research Project for Young Teachers of USTB (Fundamental Research Funds for the Central Universities) (FRF-IDRY-20-013) and 
the National Key Research Development Program of China (no. 2018YFE0101100).

\section{References}

[1] G. Feng, X. C. Wang, Y. Kang, and Z. Zhang, "Effect of thermal cycling-dependent cracks on physical and mechanical properties of granite for enhanced geothermal system," International Journal of Rock Mechanics and Mining Sciences, vol. 134, Article ID 104476, 2020.

[2] S. Zhu, J. Cheng, W. Song, and M. Borowski, "Using seasonal temperature difference in underground surrounding rocks to cooling ventilation airflow: a conceptual model and simulation study," Energy Science \& Engineering, vol. 8, no. 10, pp. 3457-3475, 2020a.

[3] S. Zhu, J. Cheng, Z. Wang, and W. Song, "Physical simulation experiment of factors affecting temperature field of heat adjustment circle in rock surrounding mine roadway," Energy Sources, Part A: Recovery, Utilization, and Environmental Effects, vol. 2020, Article ID 1760969, 18 pages, 2020b.

[4] B. Xi, Y. Wu, and S. Wang, "Experimental study on mechanical properties of granite taken from Gonghe basin, Qinghai province after high temperature thermal damage," Chinese Journal of Rock Mechanics and Engineering, vol. 39, no. 1, pp. 69-83, 2020.

[5] B. Xi, Y. Wu, and Y. Zhao, "Experimental study on the relationship between macroscopic mechanical parameters of granite and thermal shock velocity under thermal shock," Chinese Journal of Rock Mechanics and Engineering, vol. 38, no. 11, pp. 2194-2207, 2019.

[6] S. Chen, C. Yang, and G. Wang, "Evolution of thermal damage and permeability of Beishan granite," Applied Thermal Engineering, vol. 110, pp. 1533-1542, 2016.

[7] Y. Hu, Y. Hu, G. Zhao et al., "Experimental study on the mechanical properties of granite under the action of temperature and stress cycles," Chinese Journal of Rock Mechanics and Engineering, vol. 39, no. 4, pp. 705-714, 2020.

[8] Y. Chen, J. Ni, W. Shao et al., "Experimental study on the influence of temperature on the mechanical properties of granite under uniaxial compression and fatigue loading," International Journal of Rock Mechanics and Mining Sciences, vol. 56, pp. 62-66, 2012.

[9] W. G. P. Kumari, P. G. Ranjith, M. S. A. Perera et al., "Temperature-dependent mechanical behaviour of Australian Strathbogie granite with different cooling treatments," Engineering Geology, vol. 229, pp. 31-44, 2017.

[10] S. Liu and J. Xu, "An experimental study on the physicomechanical properties of two post-high-temperature rocks," Engineering Geology, vol. 185, pp. 63-70, 2015.

[11] S. Sha, G. Rong, J. Peng, B. Li, and Z. Wu, "Effect of open-fireinduced damage on Brazilian tensile strength and microstructure of granite," Rock Mechanics and Rock Engineering, vol. 52, no. 11, pp. 4189-4202, 2019.

[12] Q. Yin, J. Y. Wu, C. Zhu, and M. Hu, "Shear mechanical responses of sandstone exposed to high temperature under constant normal stiffness boundary conditions," Geomechanics and Geophysics for Geo-Energy and Geo-Resources, vol. 7, p. 35, 2021.

[13] Z. Zhu, H. Tian, N. Dong et al., "Experimental study on physical and mechanical properties of high temperature granite after water cooling," Geotechnical Mechanics, vol. 39, no. S2, pp. 169-176, 2018.

[14] D. Wang, P. Zhang, H. Pu et al., "Experimental study of micro $\mathrm{CT}$ on the evolution of coal fracture structure under temperature shock," Chinese Journal of Rock Mechanics and Engineering, vol. 37, no. 10, pp. 2243-2252, 2018.

[15] P. Jin, Y. Hu, J. Shao et al., "Experimental study on physical mechanics and permeability of granite after rapid cooling," Journal of Rock Mechanics and Engineering, vol. 37, no. 11, pp. 2556-2564, 2018.

[16] S. Tang, J. Luo, and C. Tang, "Theoretical and numerical study on the cryogenic fracturing in rock," Chinese Journal of Rock Mechanics and Engineering, vol. 37, no. 7, pp. 1596-1607, 2018.

[17] M. Cha, X. Yin, T. Kneafsey et al., "Cryogenic fracturing for reservoir stimulation-laboratory studies," Journal of Petroleum Science and Engineering, vol. 124, pp. 436-450, 2014.

[18] S. Enayatpour, E. Van Oort, and T. Patzek, "Freeze frac improves the productivity of gas shales," in Proceedings of a SPE Annual Technical Conference and Exhibition, pp. 1-17, New Orleans, Louisiana, USA, October 2013.

[19] Y. Wu, C. Tang, and J. Rutqvist, "A modeling approach for analysis of coupled multiphase fluid flow, heat transfer, and deformation in fractured porous rock," International Journal of Rock Mechanics and Mining Sciences, vol. 39, no. 4, pp. 429-442, 2002.

[20] Z. P. Bazant, H. Ohtsubo, and K. Aoh, "Stability and postcritical growth of a system of cooling or shrinkage cracks," International Journal of Fracture, vol. 15, no. 5, pp. 443-456, 1979.

[21] Y. Xu, Q. Liu, and X. Xu, "Study on thermoelastic-plastic constitutive equation of rock under the action of temperature," Journal of Liaoning University of engineering and Technology (Natural Science Edition), vol. 4, pp. 527-529, 2001.

[22] Z. Gong, W. Chen, H. Yu et al., "Study on the thermo mechanical coupled elastoplastic damage model of boom clay," Geotechnical Mechanics, vol. 37, no. 9, pp. 2433-2442, 2016.

[23] L. Liu, H. Ji, D. Elsworth, S. Zhi, X. Lv, and T. Wang, "Dualdamage constitutive model to define thermal damage in rock," International Journal of Rock Mechanics and Mining Sciences, vol. 126, Article ID 104185, 2020.

[24] S. Tang and C. Ang, "Crack propagation and coalescence in quasi-brittle materials at high temperatures," Engineering Fracture Mechanics, vol. 134, pp. 404-432, 2015.

[25] M. H. Hettema, D. V. Niepce, and K. H. A. Wolf, "A microstructural analysis of the compaction of claystone aggregates at high temperatures," International Journal of Rock Mechanics and Mining Sciences, vol. 36, no. 1, pp. 57-68, 1999.

[26] P. Li, M. Cai, Q. Guo, and S. Miao, "Characteristics and implications of stress state in a gold mine in Ludong area, China," International Journal of Minerals, Metallurgy and Materials, vol. 25, pp. 1363-1372, 2018.

[27] P. Li, M. Cai, Q. Guo, and S. Miao, "In situ stress state of the northwest region of the Jiaodong Peninsula, China from overcoring stress measurements in three gold mines," Rock Mechanics and Rock Engineering, vol. 52, pp. 4497-4507, 2019.

[28] F. Zhang, J. Zhao, D. Hu, F. Skoczylas, and J. Shao, "Laboratory investigation on physical and mechanical properties of granite after heating and water-cooling treatment," Rock Mechanics and Rock Engineering, vol. 51, no. 3, pp. 677-694, 2018.

[29] S. Yang, Y. Huang, W. Tian, P. Yin, and H. Jing, "Effect of high temperature on deformation failure behavior of granite specimen containing a single fissure under uniaxial compression," Rock Mechanics and Rock Engineering, vol. 52, no. 7, pp. 2087-2107, 2019. 
[30] L. Fan, Z. Wu, Z. Wan, and J. Gao, "Experimental investigation of thermal effects on dynamic behavior of granite," Apply Thermal Engineering, vol. 125, pp. 94-103, 2017.

[31] M. Cai, Principle and Technology of In-Situ Stress Measurement, pp. 231-244, Science Press, Beijing, China, 2000.

[32] F. Zhang, Physical and Mechanical Properties of High-Temperature Rocks after Different Cooling Treatments, Dalian University of Technology, Dalian, Liaoning, China, 2020.

[33] P. Jin, Study on Evolution of Fracture and Surrounding Rock during Seepage-Heat Transfer Process of High-Temperature Fracture Granite, Taiyuan University of Technology, Shanxi, China, 2019.

[34] D. George and B. Davood, "A new T-H-M-C model development for discrete-fracture EGS studies," Geothermal Resources Council - Transactions, vol. 36, pp. 383-392, 2012. 